\title{
Commentary on Cultural Diversity Across the Pacific: The Dominance of Western Theories, Models, Research and Practice in Psychology
}

\author{
Lisa Stewart \\ Māramatanga Consultants Ltd, Auckland, New Zealand [Iwi Affiliations: Te Ati Haunui-a-Paparangi, Ngā Puhi, Tūwharetoa]
}

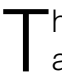
he three featured articles in the December 2010 section on cultural diversity across the Pacific address important cultural issues in psychology. Berry (2010) applied these issues to intercultural relations and acculturation, Furnham (2010) to culture shock, and Marsella and Yamada (2010) to psychopathology. The common theme among these articles was the Western-centric dominance of psychology's research, theories, models and practice, in part because of structural discrimination such as ethnocentric curricula, policies and teaching methods within academic institutions. In Aotearoa New Zealand, including mātauranga Māori (Māori knowledge) and kaupapa Māori (Māori philosophy) within curricula for clinical psychology has started to address that Western-centric dominance, but more importantly, resulted in more culturally safe and responsive psychological services being provided to Māori users of those services. The present commentary suggested that including and integrating more cross-cultural and indigenous knowledge into the tertiary curricula of applied psychology fields, such as clinical, industrial-organisational, and coaching psychology would be one way to counter the Westerncentric dominance.
\end{abstract}

Keywords: cultural diversity, discrimination, dominance, ethnocentric, indigenous, Māori

One of the common features of countries across the Pacific is ethnic and cultural diversity. Many of those countries share a long history of colonisation resulting in deculturation and often poorer socio-economic, health and employment outcomes for indigenous peoples. Many of those negative outcomes persist today, but are no longer limited to indigenous peoples. Increasingly, other minority cultural groups are feeling the impact of living in countries that are often Westerncentric in terms of the predominance (and assumed superiority) of Western systems of government and power, social structures and standards, economic systems, academic institutions, research methods and topics, and language.

In that context, psychological research and services have an important role to play; for example, understanding the processes of acculturation, the processes of culture shock, the experience of racism, prejudice and discrimination in society as well as in employment, and the poorer mental health and general wellbeing outcomes for those of
non-Western cultures. However, other disciplines such as sociology, human development and learning, and sociocultural anthropology (to name a few) also shed important light on these issues.

Until relatively recently, the research, theories, models and practice in psychology and other disciplines has been almost exclusively Western-centric; indeed, such Westerncentric psychology continues to dominate in our teaching institutions and therefore our practice. In more recent years, as researchers and practitioners from indigenous and minority cultures have come through the ranks and gained academic qualifications, some of that dominant space has been claimed back, resulting in research, theories, models and practice from a non-Western world view. Consequently, the limitations of a largely Western psychology (and other disciplines) when working with diverse ethnic and cultural groups is being increasingly recognised as poorer socio-economic, health and employment outcomes for minority groups, including indigenous peoples, persist. 
As an emerging Māori industrial-organisational psychologist, when I read the articles by Berry (2010), Furnham (2010), and Marsella and Yamada (2010), it was the theme of Western-centric dominance (and sometimes blindness) within psychology that I noticed as particularly important.

\section{Intercultural Relations and Acculturation}

Berry's (2010) intercultural strategies acculturation model includes the acculturation styles of integration, assimilation, separation, and marginalisation at an ethno-cultural group level, and multiculturalism, melting pot, segregation and exclusion at a larger, societal level. In explaining the process of acculturation, Berry asserts that 'although one group is usually dominant over the others, successful outcomes require mutual accommodation among all groups and individuals living together in a diverse society' (p. 97), that is, mutual integration, guided by a societal norm of multiculturalism. When a multicultural norm is not the on-the-ground reality, then questions arise about the adaptability of the four ethno-cultural group strategies. For example, assimilation may work for, but integration may backfire on, a group when the wider norm is that of a 'melting pot'; in contrast, separation and marginalisation may be comparatively adaptive when societal norms of segregation and exclusion are in place. Berry's model thus improves upon earlier unidirectional models of acculturation by taking into account possible interactions between styles on the one hand, and societal norms on the other.

At a more psycho-political and possibly economic level, the model raises fundamental questions about 'why' preferences for acculturation styles and societal norms exist in the first place, and why they can result in the ethnocultural group strategy chosen by the minority group. For example, what benefits might motivate a dominant culture to accommodate indigenous, immigrant or refugee (minority) groups? After all, the dominant group has the advantage of power and control of institutions, and therefore has real choice in their decision to accommodate. What degree of real choice then do minority groups have in deciding which of the four strategies to adopt? What role does social identity play in the decision-making process of minority groups, and the acculturation strategy they adopt? Do minority groups that are different in appearance, language, religion or values (from the society of settlement) really experience the same kinds of interactions as minority groups that are similar in appearance, language, religion or values, when they each choose the same acculturation style? Finally, indigenous, immigrant and refugee groups might have very different motivations for living in a particular society where the dominant culture is different to their own, which may differentially determine which acculturation style they adopt.

Reviewing the acculturation literature reveals a debate among researchers about the range of issues related to the strengths and limitations of acculturation research. For example, Padilla and Perez (2003) have further advanced our understanding by including social cognition, cultural competence, social identity and social stigma in the model. In Padilla and Perez it is noted that 'individual differences and personality characteristics [can] facilitate or retard acculturation' (p. 40). Ngo (2008) examines acculturation through an anti-oppression and social justice lens. I particularly liked Ngo's focus on procedural justice, which emphasises fair governance in social structures, processes and practices, in addition to distributive and redistributive justice (which focus on income and other resources). A procedural justice lens starts to address the issue of 'power and control' that dominant groups have on institutions and resources, against which minority groups have to contend during an acculturation process. Researchers are not exempt from reflecting on such issues (Ngo, 2008; Rudmin, 2006). In that respect, therefore, the recent emergence of non-Western — including Pacifica - researchers in the field is particularly important.

\section{Culture Shock and Race Culture Shock in Education Institutions}

Furnham's (2010) article explores one of the negative facets of acculturation - culture shock. Specifically, the focal article examined culture shock issues for foreign students studying within education institutions abroad. Furnham outlines the four main problems faced by foreign students as follows:

\begin{abstract}
First there are problems that confront anybody living in a foreign culture, such as racial discrimination, language problems, accommodation difficulties, separation reactions, dietary restrictions, financial stress, misunderstandings and loneliness. Second, there are the difficulties that face all late adolescents and young adults, whether they are studying at home or abroad, in becoming emotionally independent, selfsupporting, productive and a responsible member of society. Third, there are academic stresses when students are expected to work very hard, often under poor conditions, with complex material. Fourth, the national or ethnic role of overseas students is often prominent in their interactions with host members. (p. 89)
\end{abstract}

Of these four problems, ethnicity features in two of them, and one of the patterns noted by Furnham from the research literature is that foreign students generally seem to experience higher levels of physical and mental ill-health and academic problems than other students. Although the cause of these difficulties has not yet been established, strong social support networks are believed to be one component to helping foreign students survive culture shock.

I believe there are parallel issues for Māori students in tertiary education institutions in Aotearoa New Zealand, including those studying psychology. Torres (2009) refers to 'race culture shock', in which a student in an [education] institution in their own country is in the racial minority. Māori psychology students are certainly in the 
minority in our country, and my own experience of being both a psychology student as well as a Māori member of staff providing academic and learning support services to Māori supports the similarity of culture shock experiences faced by foreign students. Māori psychology student and staff experiences of institutional racism, or what the Human Rights Commission (2011) now refers to as structural discrimination, is the underlying theme discussed by Gavala and Taitimu (2007), Levy (2002), and Milne (2005). Sisley and Waiti (1997) found structural discrimination within the broader education sector, along with the Human Rights Commission (2011), which also found structural discrimination throughout the public sector in Aotearoa New Zealand.

Structural discrimination is the 'practices, norms and behaviours within institutions and social structures which have the effect of denying rights or opportunities to members of minority groups while serving to advantage members of the majority group' (Human Rights Commission, 2011 , p. 4). An example within the education sector is ethnocentric curricula, policies and teaching methods, and for Māori and other minority ethnic groups (including foreign students), this can be experienced in the same way as culture shock. Although structural discrimination is largely unintentional, it nevertheless results in disadvantage to Māori, and other minority ethnic groups.

Certainly ethnocentric curricula, policies and teaching methods within clinical psychology are some of the issues highlighted by Gavala and Taitimu (2007), Levy (2002), and Milne (2005). In fact, the perspectives of some of Milne's (2005) research participants were not complimentary of psychology, and some participants felt it was a dangerous profession for Māori because of the complete absence of mātauranga Māori (Māori knowledge) and kaupapa Māori (Māori philosophy) psychology within tertiary education programs and clinical practice models and methods. Not only did Māori psychology students and professionals risk being 'colonised' again by Western psychology, Māori clients of clinical services and the wider Māori community were deeply suspicious of Māori psychologists because of the damaging outcomes to the wellbeing of those clients and their whānau (family) as a result of receiving psychological services.

Clinical psychology teaching and training has improved in recent years as Māori clinical psychologists started actively developing a body of Māori psychology knowledge and practice, and as more Māori clinical teaching staff came into tertiary institutions. However, in the discipline of industrial-organisational (I-O) psychology, ethnocentric curricula, policies and teaching methods are still the norm. As long as Māori I-O psychology students remain extremely under-represented in tertiary education, and there are no Māori I-O teaching staff in psychology departments, this situation is likely to remain and Māori I-O students will continue to experience structural discrimination and the effects of race culture shock.

\section{Blindness of Western-Developed Psychiatric/Psychological Assessments}

The importance of Marsella and Yamada's (2010) discussion about ethnocentric blindness or bias in Western psychiatry and psychology cannot be underestimated in terms of the potential for harm to non-Western and especially indigenous clients. In particular, Marsella and Yamada's caution that '... Western psychiatric assumptions and practices may be relevant and accurate within a Western cultural context, but this does not mean they are relevant or accurate in other contexts. We must not mistake "power" and "dominance" for accuracy' (p. 106). This caution reminds us that although the Pacific region is culturally diverse, the dominant culture and power base in many Pacific countries is still Western (individualistic). By including information about Native Hawaiian worldviews about mental health and wellbeing, Marsella and Yamada claim valuable space for an indigenous non-Western voice to be heard, as well as increasing the visibility of the ethnocentric bias of psychology.

The ethnocentric bias implicit in Western assessment tools in both clinical and I-O psychology in relation to Māori in Aotearoa New Zealand is examined next.

\section{The Clinical Setting}

In the clinical setting, the American Psychiatric Association's various Diagnostic and Statistical Manuals of Mental Disorders (DSMs) are a listing of psychiatric disorders, including diagnostic criteria and other features such as prevalence, family, age, gender and cultural features. The implicit model underpinning the DSMs is the biomedical model of health, and the underlying assumption is that indicators of mental disorders are uniform and universal. Notwithstanding the important role the DSMs have played in defining and furthering understanding of mental disorders, criticism of some of their aspects abounds. For example, Follette and Houts (1996) assert that failure by the American Psychiatric Association to explicitly state the theoretical basis (especially of the DSM-IV), discourages any challenge to the biomedical model's role in mental health disorders and the universality assumption. In addition, despite attempts (particularly with the DSMIII and DSM-IV) to incorporate features designed to increase their cross-cultural validity, concerns remain about the appropriateness of using the DSMs with non-Western clients (Marsella \& Yamada, 2010; Nikelly, 1992; Thakker \& Ward, 1998).

For many years, Māori psychiatrists, psychologists and other mental health workers have recognised the limitations of using the DSMs with Māori clients, in part because of the Western ethnocentric values, assumptions and processes underpinning them, but also because the health outcomes were unsatisfactory (Durie, 2009). In response to those limitations, Kingi and Durie (2002) developed a Māori measure of mental health outcomes, called 'Hua Oranga' to contribute to achievement of better mental 
health outcomes for Māori. Hua Oranga departs from the biomedical model, and instead is founded on a Māori model of health called Te Whare Tapa Whā, which includes the following four components: taha wairua (spiritual dimension), taha hinengaro (mental dimension), taha tinana (physical dimension), and taha whānau (family dimension).

Te Whare Tapa Whā provides a more holistic understanding of general health and wellness for Māori clients, and in the mental health context, considers more than just the mental dimension of health and wellness. By using Te Whare Tapa Whā to underpin Hua Oranga, Kingi and Durie (2002) explicitly acknowledge that factors other than physiology (from the tinana/physical dimension) contribute to mental health disorders. Additionally, when it comes to health outcomes, Hua Oranga takes a triangulated approach, and considers the views of the clinician, the client, and their family. By contrast, the DSMs only consider the view of the clinician. Clearly, the holistic approach of Hua Oranga, based on the foundation of a Māori model of health, ensures the intended principles of wellness, cultural integrity, specificity, relevance, and applicability are upheld when working with Māori clients.

\section{The Workplace Setting}

In the workplace, a range of psychometric assessments are available to measure occupational stress. Examples of such psychometric assessments include Osipow and Spokane's (1992) revised Occupational Stress Inventory (OSI-R), Williams and Cooper's (1998) Pressure Management Indicator (PMI), Cartwright and Cooper's (2002, as cited in Johnson \& Cooper, 2003) ASSET (An Organizational Stress Screening Tool), and Roesch and Rowley's (2005) Stress Appraisal Measure. These occupational stress assessments are developed in Western countries and norm reference groups established for use with the Aotearoa New Zealand population. One assumption of the norming process is that because a test-taker's scores are compared with scores of others from that same norm group (e.g., Māori workers), the test results and their interpretation are valid for that norm group regardless of any cultural differences in the experience of occupational stress. The problem with Western-developed psychometric assessments of occupational stress is that they fail to capture aspects of occupational stress which are experienced very differently by Māori (and other non-Western) workers in Aotearoa New Zealand.

In order to capture those different occupational stress experiences for Māori, Stewart (2011) developed a culturally responsive measure of occupational stress and wellbeing for Māori called 'Mahi Oranga' which is founded on Te Whare Tapa Whā. As part of the preliminary work of developing Mahi Oranga for use in the public sector (specifically health and disability), Stewart's focus groups of research participants discussed incidents of institutional racism (or structural discrimination), a lack of cultural competence of their non-Māori colleagues, exploitation of the dual set of competencies Māori workers bring to the table, and a lack of respect for Māori cultural norms, values and knowledge in the workplace. These workplace experiences are common for many non-Western workers in Aotearoa New Zealand; however, ethnocentrically biased psychometric assessments fail to capture those experiences. Mahi Oranga addresses these issues in a section measuring cultural safety, which has been formally recognised in Aotearoa New Zealand since 1992, and is defined by the Nursing Council of New Zealand (2005) as 'the effective nursing practice of a person or family from another culture, and is determined by that person or family' (p. 4).

For many years, Māori nurses observed their nonMāori colleagues engaging with Māori patients in a way that lacked awareness and respect for Māori cultural norms, values and knowledge. The spiritual and psychological wellbeing of those Māori patients decreased, resulting in a slower return to physical health, and a lack of trust in and willingness to engage with mainstream health services in the future. Although the focus of cultural safety has usually been the experience of patients or recipients of healthcare services, Mahi Oranga specifically turns that focus to the experience of Māori workers with their colleagues and managers. Additionally, although cultural safety is a widely accepted concept in the health and disability sector, it is gaining increasing recognition in other public sector services, including for example education and justice.

\section{Where to From Here?}

Structural discrimination is one of the reasons why Western-centric theories, models, research and practice are so dominant in psychology, and because the discrimination is structural and systemic, this bias largely remains invisible to Western academics, researchers and practitioners. Although unintentional, structural discrimination within our teaching (and other) institutions nevertheless results in disadvantage to nondominant groups, which in psychology has the unintended follow-on effect of psychological services not always being culturally responsive for our clients. While this is changing within some psychological disciplines, such as clinical psychology, there is still some way to go for disciplines such as I-O psychology, and emerging psychological disciplines such as coaching psychology.

Part of the answer lies in the work of Triandis and Brislin (1984) and other cross-cultural psychologists, as well as in the newer field of indigenous psychology. However, being separate fields of study, there is no guarantee that this research and knowledge will be integrated into teaching of applied disciplines such as I-O psychology and others. In addition, while some of the knowledge from these fields is included in our tertiary curricula, it is more often presented in a theoretical rather than an applied context. 
As a broad field of social science, the theories, models, research and practice of psychology provides a valuable service to our diverse communities across the Pacific. It is incumbent upon us then, to reflect on how the dominance and bias of Western psychology impacts our clients from non-Western cultures. Applied psychologists from indigenous communities such as Māori, Native Hawaiian, Native American Indian and the Pacific Islands, are making a difference at the front lines. However, indigenous and other minority group knowledge is only slowly being included in our tertiary curricula and therefore into Western practice. We have a long way to go, but inroads have been made. Long may it continue.

\section{References}

Berry, J.W. (2010). Intercultural relations and acculturation in the Pacific region. Journal of Pacific Rim Psychology, 4(2), 95-102. doi:10.1375/prp.4.2.95

Durie, M. (2009). Māori knowledge and medical science. In M. Incayawar, R. Wintrob, \& L. Bouchard (Eds.), Psychiatrists and traditional healers: Unwitting partners in global mental health (pp. 237-249). Chichester, United Kingdom: John Wiley and Sons.

Follette, W.C., \& Houts, A.C. (1996). Models of scientific progress and the role of theory in taxonomy development: A case study of the DSM. Journal of Consulting and Clinical Psychology, 64(6), 1120-1132.

Furnham, A. (2010). Culture shock: Literature review, personal statement and relevance for the South Pacific. Journal of Pacific Rim Psychology, 4(2), 87-94. doi:10.1375/ prp.4.2.87

Gavala, J., \& Taitimu, M. (2007). Training and supporting a Māori workforce. In I. Evans, J. Rucklidge, \& M. O’Driscoll (Eds.), Professional practice of psychology in Aotearoa New Zealand (pp. 229-244). Wellington, New Zealand: The New Zealand Psychological Society.

Human Rights Commission. (2011). A fair go for all? Structural discrimination and systemic barriers to ethnic equality. Wellington, New Zealand: Author. Retrieved from http:// www.hrc.co.nz/race-relations/structural-discriminationthe-elephant-in-the-room/

Johnson, S., \& Cooper, C. (2003). The construct validity of the ASSET stress measure. Stress and Health, 19(3), 181-185. doi:10.1002/smi.971.

Kingi, T.K., \& Durie, M. (2000). 'Hua Oranga': A Māori measure of mental health outcomes. Palmerston North, New Zealand: Te Pūmanawa Hauora, School of Māori Studies, Massey University.

Levy, M. (2002). Barriers and incentives to Maori participation in the profession of psychology: A report for the New Zealand Psychologists Board. Hamilton, New Zealand: Māori and Psychology Research Unit, University of Waikato.

Marsella, A.J., \& Yamada, A.M. (2010). Culture and psychopathology: Foundations, issues, directions. Journal of Pacific Rim Psychology, 4(2), 103-115. doi:10.1375/ prp.4.2.103

Milne, M. (2005). Māori perspectives on kaupapa Māori and psychology: A discussion document. Wellington, New Zealand: New Zealand Psychologists Board.

Ngo, V. H. (2008). A critical examination of acculturation theories. Critical Social Work, 9(1). Retrieved from http://www.uwindsor.ca/criticalsocialwork/a-criticalexamination-of-acculturation-theories

Nikelly, A.G. (1992). Can DSM-III-R be used in the diagnosis of non-Western patients? International Journal of Mental Health, 21(1), 3-22.

Nursing Council of New Zealand. (2005). Guidelines for cultural safety, the Treaty of Waitangi, and Maori health in nursing education and practice. Retrieved from http://www. nursingcouncil.org.nz/download/97/cultural-safety09. pdf

Osipow, S., \& Spokane, A. (1992). Occupational Stress Inventory manual: Research version. Odessa, FL: Psychological Assessment Resources.

Padilla, A. M., \& Perez, W. (2003). Acculturation, social identity, and social cognition: A new perspective. Hispanic Journal of Behavioural Sciences, 25(1), 35-55. doi:10.1177/ 0739986303251694

Roesch, S.C., \& Rowley, A.A. (2005). Evaluating and developing a multidimensional, dispositional measure of appraisal. Journal of Personality Assessment, 85(2), 188-196. doi:10.1207/s15327752jpa8502_11

Rudmin, F.W. (2006). Debate in science: The case of acculturation. In Anthroglobe Journal. Retrieved from http://www. anthroglobe.info/docs/rudminf_acculturation_061204. pdf

Sisley, R., \& Waiti, D. (1997). Te pikaunga-mahi me te kohukihuki [Workload and stress]: A national survey of Maori ASTE Te Hau Takitini o Aotearoa members. Wellington, New Zealand: Association of Staff in Tertiary Education, New Zealand Council for Educational Research.

Stewart, L. (2011). Developing Mahi Oranga: A culturally responsive measure of Māori occupational stress and wellbeing. A thesis submitted in partial fulfilment of the requirements for the degree of Masters of Arts in Psychology at Massey University, New Zealand.

Thakker, J., \& Ward, T. (1998). Culture and classification: The cross cultural application of the DSM-IV. Clinical Psychology Review, 18(5), 501-529.

Torres, K. (2009). 'Culture shock': Black students account for their distinctiveness at an elite college. Ethnic and Racial Studies, 32(5), 883-905.

Triandis, H., \& Brislin, R. (1984). Cross cultural psychology. American Psychologist, 39(9), 1006-1016. doi:10.1037/0003066X.39.9.1006

Williams, S., \& Cooper, C. (1998). Measuring occupational stress: Development of the Pressure Management Indicator. Journal of Occupational Health Psychology, 3(4), 306-321. 